\title{
Home Health Nurse Specialist
}

National Cancer Institute

\section{Source}

National Cancer Institute. Home Health Nurse Specialist. NCI Thesaurus. Code C20838.

Home health nursing refers to the practice of nursing applied to a client with a health deficit in the client's place of residence or appropriate community site. The graduateprepared clinical specialist in home health nursing can and may be asked to perform all the functions of a generalist. In addition, the clinical specialist possesses substantial clinical experience with clients who are individuals, families, and groups. The clinical specialist has expertise in the process of case management, consultation, collaboration, and education of clients, staff, and other health professionals. In addition, the clinical specialist has proficiency in planning, implementing, and evaluating programs, resources, services, and research for health care delivery to complex clients. (ANCC) 